\title{
Article \\ Improvement of an InfraRed Pyroelectric Detector Performances in THz Range Using the Terajet Effect
}

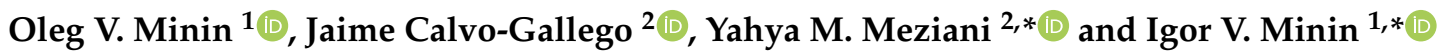 \\ 1 School of Nondestructive Testing, Tomsk Polytechnic University, Lenin Avenue, 30, 634050 Tomsk, Russia; \\ oleg.minin@ngs.ru \\ 2 NanotechGroup, Facultad de Ciencias, Salamanca University, Plaza de la Merced, Edificio Trilingüe, \\ 37008 Salamanca, Spain; jaime.calvo@usal.es \\ * Correspondence: meziani@usal.es (Y.M.M.); prof.minin@gmail.com (I.V.M.)
}

check for updates

Citation: Minin, O.V.; Calvo-Gallego,

J.; Meziani, Y.M.; Minin, I.V.

Improvement of an InfraRed

Pyroelectric Detector Performances

in $\mathrm{THz}$ Range Using the Terajet Effect.

Appl. Sci. 2021, 11, 7011. https://

doi.org/10.3390/app11157011

Academic Editor: Akram Alomainy

Received: 7 July 2021

Accepted: 27 July 2021

Published: 29 July 2021

Publisher's Note: MDPI stays neutral with regard to jurisdictional claims in published maps and institutional affiliations.

Copyright: (c) 2021 by the authors. Licensee MDPI, Basel, Switzerland.

This article is an open access article distributed under the terms and conditions of the Creative Commons Attribution (CC BY) license (https:// creativecommons.org/licenses/by/ $4.0 /)$.

\begin{abstract}
An infrared (IR) pyroelectric detector was investigated for terahertz (THz) detection using the principle of the terajet effect, which focuses the beam beyond the diffraction limit. The terahertz beam was coupled to the detector's optical window through a two-wavelength-dimension dielectric cubic particle-lens based on the terajet effect. We experimentally demonstrate an enhancement of about $6 \mathrm{~dB}$ in the sensitivity under excitation of $0.2 \mathrm{THz}$ without degradation of the noise equivalent power value. The results show that the proposed method could be applied to increase the sensitivity of various commercial IR sensors for $\mathrm{THz}$ applications that do not require modification of the internal structure, and it may apply also to acoustics and plasmonic detectors.
\end{abstract}

Keywords: terajet; point contact detector; terahertz; millimeter wave; dielectric cube

\section{Introduction}

Terahertz (THz) waves have recently received unprecedented interest in product quality control, medicine, biology, 5G and 6G communication, nondestructive testing, and homeland security applications, to name a few [1-17], that cannot be achieved at optical or infrared (IR) electromagnetic bands. THz detectors play a key role in terahertz technologies. The Golay cell [18] is a "photo-acoustic" device commonly used in the THz range. Bolometers, where the conductivity of the material changes with temperature induced by terahertz radiation, are cooled detectors and highly sensitive. The pyroelectric detector (PD), in which the output current is proportional to the changing rate of temperature of film material [19], has some important advantages such as room temperature operation and low cost. Various types of special THz PDs were developed in the last decade: a PD based on lithium tantalate crystal and film was considered in [20], a tetraaminediphenyl-based PD was investigated in [21], and a PD for THz time-domain spectroscopy (TDS) systems was developed in [22,23]. A PD consists of a pyroelectric polyvinylidene fluoride (PVDF) film coated with a metal oxide layers. It has been shown that to decrease the noise equivalent power value (NEP), the thickness of pyroelectric film should be reduced. However, all these and other similar developments require either the development of a new detector design or replacement of the material in the existing commercial detector. Moreover, the present PD, designed especially for THz range, is expensive and lacks reliability. Presently, PDs are one of the most used devices in uncooled IR detectors, providing a high efficiency of detection of the illuminated radiation, relative short response time, high signal-to-noise ratio, low cost, and high reliability [24-27].

Usually, the responsivity of PDs in the THz range is improved by: (i) a traditional gate structure with the grating-gate structure [28]; (ii) implementation of a silicon lens [29], diffractive grating [30], or wavelength-scaled dielectric cube [31,32]; and (iii) internal integration of an antenna structure [33,34]. All these methods, except for [31,32], require a change in the internal structure of the $\mathrm{THz}$ detector and its design and are intended for 
special operation in the THz range. In our work, we consider the use of an IR detector for operation in a non-standard THz range not intended by the detector manufacturer and show for the first time that without changing its internal design, it is possible to increase its sensitivity not in the IR but in the THz range. A THz detector based on an IR-PD (LHI778, Perkinelmer), initially designed for a wavelength range of 7-14 $\mu \mathrm{m}$ and used in THz imaging applications, was studied in [35]. A special amplification circuit to amplify and capture the signal from the sensor was designed. A responsivity of about $1.2 \mathrm{kV} / \mathrm{W}$ at $1.89 \mathrm{THz}$ was achieved. However, direct application of conventional IR-PD to the THz band faces a problem of decreasing the detector's sensitivity.

Commercial IR-PD (MG-33) is a good substitute for special THz detector. Though it is designed for IR, it retains sensitivity at THz frequencies. Single-element IR-PD has the operation wavelength range between 3 and $20 \mu \mathrm{m}$ [36] and is based on a free organic films of the PVDF type [23]. An active area of $1 \times 1 \mathrm{~mm}$, ensure an NEP sensitivity threshold in the IR range lower than $5 \times 10^{-10} \mathrm{~W} \cdot \mathrm{Hz}^{0.5}$ and a sensitivity greater than $10^{5} \mathrm{~V} / \mathrm{W}$ [37]. To enhance the PD sensitivity in the THz band [38,39], a combination of a MG-33 detector and a metasurface-enabled absorber was considered in [40]. It was demonstrated that the efficient frequency- and polarization-selective detection in the range of $100-180 \mathrm{GHz}$ with a degradation of NEP by a factor 2 . However, this required a change in both the design of the detector itself (including the diameter of the optical window being specially increased from $3.5 \mathrm{~mm}$ to $5 \mathrm{~mm}$ in [40]) and the development of a new absorber. In addition, due to the nature of the metasurface, the detector has a pronounced resonance character.

The aim of this work is to demonstrate the possibility of the effective use of commercially IR-PD in the $\mathrm{THz}$ range without changing their internal design. One of the new approaches to increase the sensitivity of $\mathrm{THz}$ detector is based on the so-called terajet effect [41-44]. This effect is based on a reduction of the focused beam size caustic up to the sub-diffraction value at a distance close to the shadow surface of the wavelength-scaled particle-lens made from a conventional dielectric material [45]. The physics of the terajet effect is a complex interference and scattering phenomenon. The constructive interference between the incident field and diffracted and scattered fields by the wavelength-scaled dielectric particle leads to such a localization of electromagnetic wave in the form of terajet with a beam waist up to sub-diffraction limit. Like photonic jets in optics, it localizes intense electromagnetic beams formed near the shadow surface of a dielectric particle with a size greater or even equal to the illumination wavelength and propagating into the environment. It has recently been demonstrated that placing a dielectric cube in front of a sensitive area of strained silicon field effect transistor [32,46] and point contact detector [31] allows the sensitivity of $\mathrm{THz}$ detectors to be increased due to the localization of the incident radiation with the slight decreasing of NEP value. Here, we demonstrate that this method allows one to increase the sensitivity of IR commercial detectors in the $\mathrm{THz}$ range with room temperature operation.

\section{Experimental Setup and Methods}

The basic scheme of the experimental setup is shown in Figure 1a, where a terahertz source based on a backward-wave oscillator [47] (BWO) "OV-1" from Istok Co. was use to excite the detector. It was chosen because of its special features such as stability, relative high output power (6-15 $\mathrm{mW})$, good wave-front quality and wavelength tunability between 177 and $260 \mathrm{GHz}$. A certified attenuator was coupled to the BWO and used to control and measure the emitted power. The horn antenna of BWO was placed at a distance of approximately $210 \mathrm{~mm}$ from the detector's window (which corresponds to the far-field condition) to form a quasi-plane wavefront. A commercial Infrared PD (MG-33) was used for the detection of $\mathrm{THz}$ radiations (Figure 1b,c). The PD-MG33 sensor has a standard KT-3 package [36], which contains a primary amplifier located on the sensor chip, as shown in Figure 1. The THz beam was modulated by a chopper at $20 \mathrm{~Hz}$ rate, and the photoresponse was measured by a micro-voltmeter as well as an oscilloscope. A dielectric wavelength-scaled particle in the form of a cube was glued and placed directly on the PD 
window made of germanium and with a thickness around $70 \mu \mathrm{m}$. To increase the coupling efficiency of the PD with $\mathrm{THz}$ radiation source at $\lambda=1.5 \mathrm{~mm}$ (frequency of about $0.2 \mathrm{THz}$ ), we use a terajet formed by a polytetrafluoroethylene (PTFE) cube with a dimension equal to $2 \lambda$. The cubic shape of the dielectric particle was chosen because of the manufacturing simplicity and its attachment to the flat surface of the PD filter window. The refractive index of PTFE is $\mathrm{n}=1.41$ [48-50], and the beam waist of the terajet (in the unit of full width at half maximum) for the dimension of the PTFE cube is about $0.5 \lambda$ [41-44]. The maximum field intensity enhancement was observed at the distance of about $0.7 \mathrm{~mm}$ from the shadow surface of the cuboid [41-44] — see Figure 1c, taking into account the features of the constructive assembly of the PD shown in Figure 1a (minimal distance between window's shadow surface and sensitive element is not equal to zero and has a fixed value (d), fixed by the manufacturer technology).

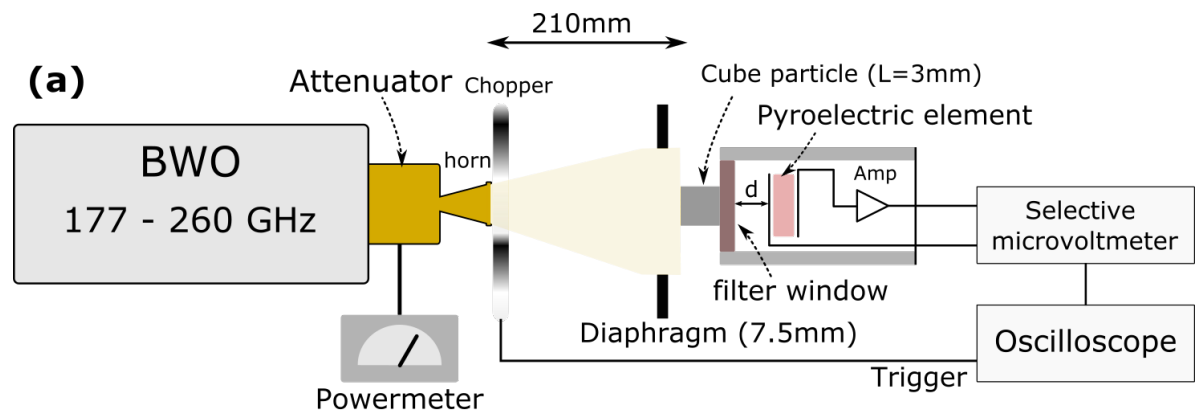

(b) KT-3 package

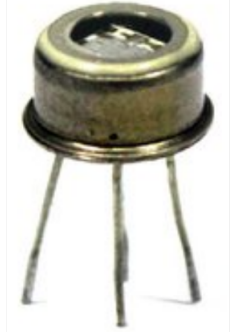

(c) top view of the PD

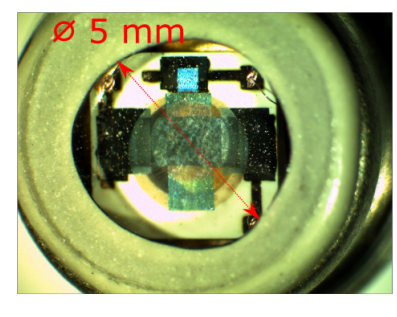

Figure 1. Schematic description of the terahertz measurement setup where a commercial PD MG-33 combined with the dielectric particle (not in scale) was used as a detector, (a); MG-33 detector at the standard KT-3 package (b) and the top view of the PD with standard-diameter of window of $\varnothing=5 \mathrm{~mm}$, (c).

Full-wave electromagnetic simulations were performed using the software CST where the Maxwell equations were solved. It is a well known solver that is used to analyze electrically large structures where the physical size is much larger than the wavelength. The incident beam was considered as a plane propagating along the $z$ direction (Figure 2a). Since the PTFE is a commercial one, the refractive index could vary depending on the density of the material, and two values of the refractive index (1.41 and 2.1) were simulated. Figure $2 b$ shows the intensity of the electric field along the $z$ direction for two values of the refractive index. A maximum was observed around $z_{\max }=1.7 \mathrm{~mm}$ and $z_{\max }=0.5 \mathrm{~mm}$ for $n=1.41$ and 2.1, respectively. Those values are in agreement with the one found experimentally $(0.7 \mathrm{~mm})$. Figure $2 \mathrm{c}$ shows the intensity of the electric field fin and the $x z$ plane for the cube with a length equal to $2 \lambda$ and $n=1.41$. As can be seen in the figure, the introduction of a cube induces the formation of an area in which the electric field is concentrated as a result of the terajet beam effect. The obtained gain from the simulation was around 9.5 and $12 \mathrm{~dB}$ for $n=1.41$ and 2.1, respectively. The expected beam size was $1.44 \times 1.38 \times 6.15 \mathrm{~mm}^{3}$ and $1.22 \times 0.76 \times 1.84 \mathrm{~mm}^{3}$ in the $x y z$ directions and for $n=1.41$ and 2.1 , respectively. 
(a)

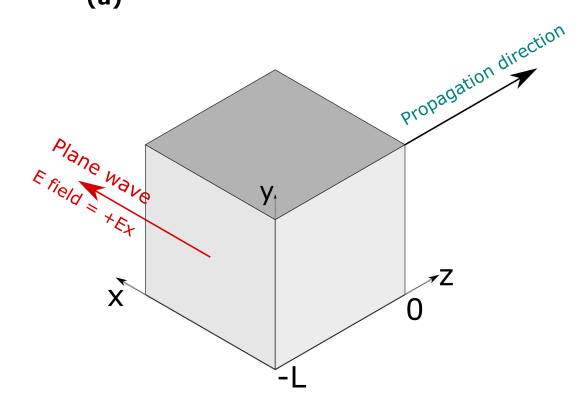

(b)

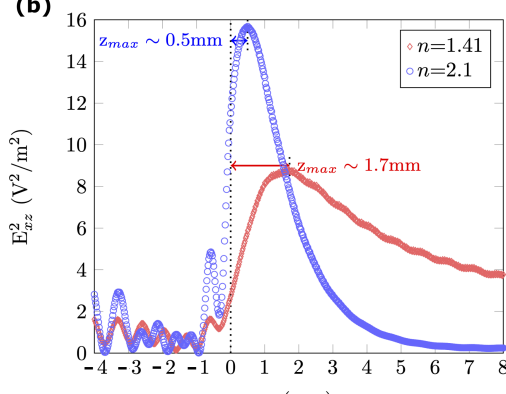

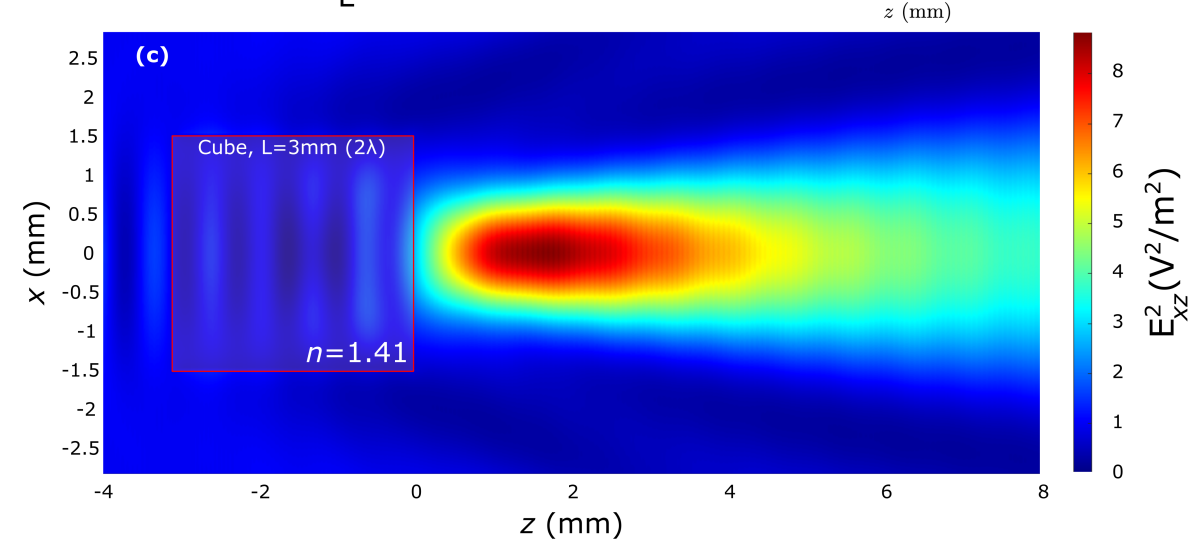

Figure 2. (a) Sketch description of the cube with the plane wave and the propagation directtion used in the simulations, (b) Electric field intensity along the $x z$ direction versus the $z$ direction for the case of two refractive index $(n=1.4$ and 2.1) and (c) the terajet formation from the cube with 2-wavelength dimensions by the finite integral technique realized in commercial software-the CST Microwave Studio.

\section{Results and Discussions}

The detection measurements were performed with and without the cube particle with different emitted power. The measurements (Figure 3) show a linear dependence of the voltage $(\mathrm{U})$ with the power at $\lambda=1.5 \mathrm{~mm}$ (this value gives the maximum output power from the BWO). The method for measuring the NEP was similar to that described in Reference [40]. The idea of this configuration is to exploit a dielectric PTFE particle that has a wavelength-scale size to concentrate the radiating $\mathrm{THz}$ waves into the sensitive area of PD with a diffraction-limited value. This allows increasing the intensity of signal to be measured, such that the signal-to-noise ratio (SNR) can be improved.

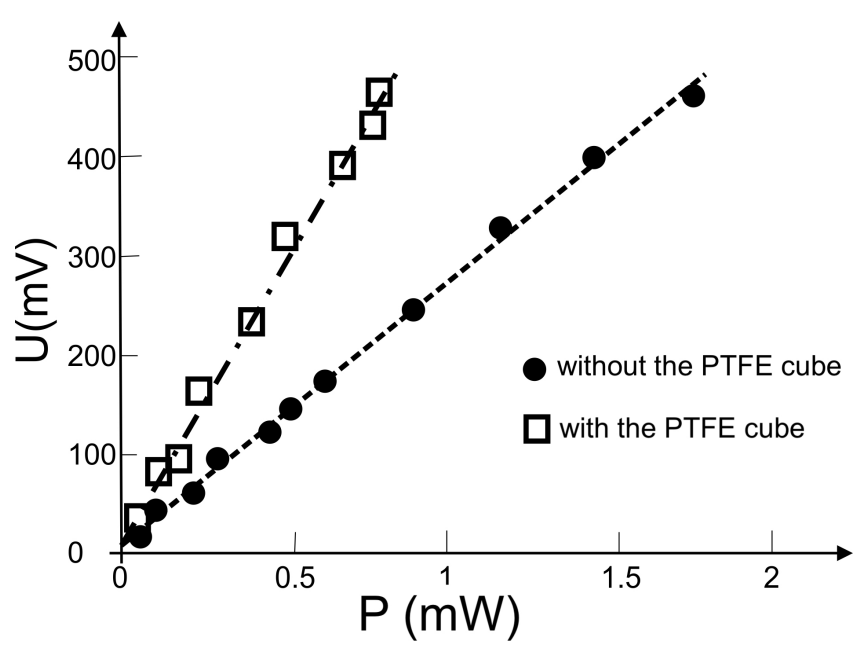

Figure 3. The voltage-power characteristics of the PD MG-33 measured at the wavelength of $\lambda=1.5 \mathrm{~mm}$. NEP $\approx 6 \times 10^{-9} \mathrm{~W} \cdot \mathrm{Hz}^{-1 / 2}$, Sens $\approx 2.6 \times 10^{5} \mathrm{~V} / \mathrm{W}$ for MD without the particle. 
Figure 4 shows the measured photoresponse without the cube (black) and with the cube (red). To demonstrate the sensitivity enhancement, the detector was excited by the source at its lowest power idem when the signal from the receiver (without a particle) was at the noise level. Then, we placed the particle and looked at the increase in the signal and the noise level. The measured amplitude with the cube was $6.1 \pm 0.06 \mathrm{mV}$, which was $5.6 \mathrm{~dB}$ higher than that without the enhancer. The standard error was calculated from eight distinct measurements and a Student's ( $t$ ) coefficient [51] of 2.132, corresponding to a $90 \%$ two-sided confidence interval. The standard deviations of the amplitude were measured for the cases without and with the PTFE particle, respectively. These results indicate that the proposed technique can enhance the detected THz intensity of $5.6 \mathrm{~dB}$ at $0.2 \mathrm{THz}$ for MG-33 PD. Similar results were obtained for the MG-30 sensor, which has the same internal design as the MG-33 but differs only in standard 1203.15-1 package. The obtained gain is below the theoretical one because of the uncertainties in the setup such the dimension of the active area of the PD, and the distance from the optical window to the active element of the PD was fixed by the manufacturer and unknown. Furthermore, we did not verify the refractive index of particle material experimentally. From a practical point of view, it is quite difficult to perform a precise relative positioning between the cuboid and detector to ensure that the detector is located just at the point of maximum electric field generated by the cuboid. However, knowing the gain obtained experimentally, we can obtain an estimate of the real distance between the cuboid and the detector by looking at Figure 2b.

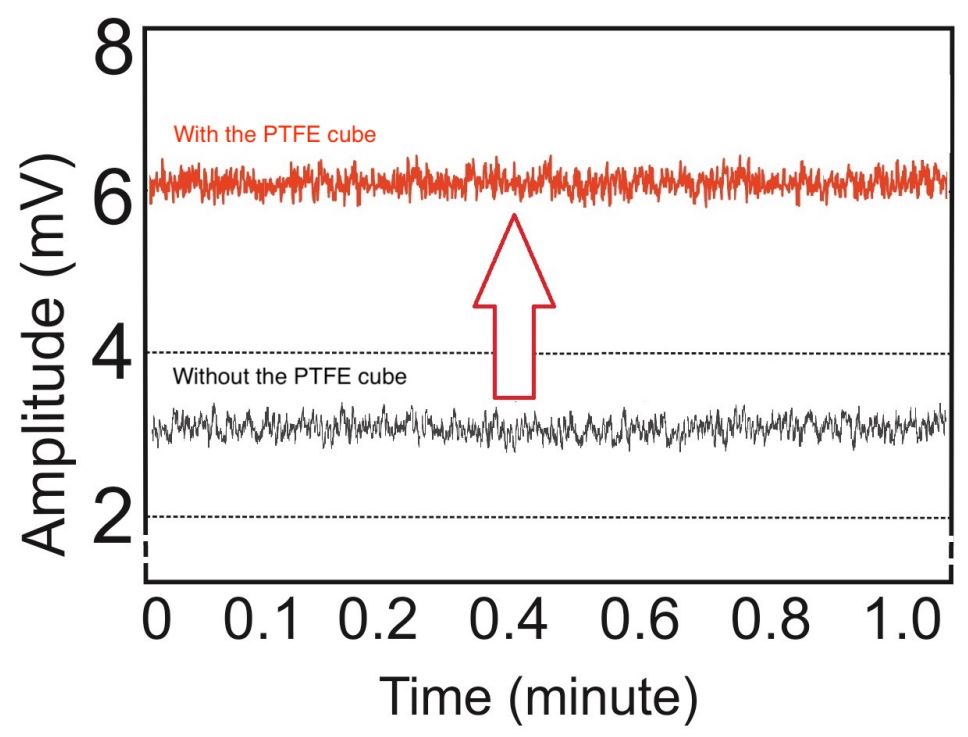

Figure 4. Measured amplitude without (black) and with (red) the PTFE cube at $200 \mathrm{GHz}$.

\section{Conclusions}

Commercial IR-PD performance was investigated in the $\mathrm{THz}$ range using the terajet effect. A gain enhancement of about $6 \mathrm{~dB}$ was experimentally obtained under excitation of $0.2 \mathrm{THz}$ using the commercial PD without degradation of its NEP value. The research results confirm the prospects of pushing the operation frequency of the $\mathrm{PD}$ to the $\mathrm{THz}$ range where no design modification was required. The entire setup offers a cost-effective solution for sensitivity enhancement of IR-PDs in THz, which can be applied in many research fields, including imaging systems, $\mathrm{THz}$ wireless communication, etc. The method of increasing the sensitivity of commercial sensors can also be applied to both acoustics and plasmonics devices.

Author Contributions: Conceptualization, I.V.M. and O.V.M.; idea, I.V.M. and O.V.M.; formal analysis, all authors; investigation, all authors; Experiments, I.V.M. and O.V.M.; writing-review and editing, I.V.M. and Y.M.M.; terajet simulations, J.C.-G. All authors have read and agreed to the published version of the manuscript. 
Funding: This research was supported by the Tomsk Polytechnic University development program. This research was funded by the Ministerio de Ciencia, Innovación y Universidades grant number RTI2018-097180-B-100 and by Junta de Castilla y León grant numbers SA256P18 and SA121P20.

Institutional Review Board Statement: Not applicable.

Informed Consent Statement: Not applicable.

Data Availability Statement: The data that support the findings of this study are available from the corresponding author upon reasonable request.

Conflicts of Interest: The authors declare no conflict of interest.

$\begin{array}{ll}\begin{array}{l}\text { Abbreviations } \\ \text { The following abbreviations are used }\end{array} \\ \text { BWO } & \text { Backward Wave Oscillator } \\ \text { IR } & \text { Infrared } \\ \text { NEP } & \text { Noise Equivalent Power } \\ \text { PD } & \text { Pyroelectric Detector } \\ \text { PTFE } & \text { Polytetrafluoroethylene } \\ \text { SNR } & \text { Signal-to-noise ratio } \\ \text { TDS } & \text { Time-domain spectroscopy } \\ \text { THz } & \text { Terahertz }\end{array}$

\section{References}

1. Dhillon, S.S.; Vitiello, M.S.; Linfield, E.H.; Davies, A.G.; Hoffmann, M.C.; Booske, J.; Paoloni, C.; Gensch, M.; Weightman, P.; Williams, G.P.; et al. The 2017 terahertz science and technology roadmap. J. Phys. D Appl. Phys. 2017, 50, 043001. [CrossRef]

2. Kawase, K.; Ogawa, Y.; Watanabe, Y.; Inoue, H. Non-destructive terahertz imaging of illicit drugs using spectral fingerprints. Opt. Express 2003, 11, 2549-2554. [CrossRef] [PubMed]

3. Ferguson, B.; Wang, S.; Gray, D.; Abbot, D.; Zhang, X.C. T-ray computed tomography. Opt. Lett. 2002, 27, 1312-1314. [CrossRef] [PubMed]

4. Federici, J.; Moeller, L. Review of terahertz and subterahertz wireless communications. J. Appl. Phys. 2010, 107, 111101. [CrossRef]

5. Siegel, P. Terahertz technology in biology and medicine. IEEE Trans. Microw. Theory Tech. 2004, 52, 2438-2447. [CrossRef]

6. Hu, B.B.; Nuss, M.C. Imaging with terahertz waves. Opt. Lett. 1995, 20, 1716-1718. [CrossRef]

7. Chernomyrdin, N.; Kucheryavenko, A.; Kolontaeva, G.; Katyba, G.; Karalkin, P.; Parfenov, V.; Gryadunova, A.; Norkin, N.; Smolyanskaya, O.; Minin, O.V.; et al. A potential of terahertz solid immersion microscopy for visualizing sub-wavelength-scale tissue spheroids. In Unconventional Optical Imaging; International Society for Optics and Photonics: Bellingham, WA, USA, 2018. [CrossRef]

8. Minin, I.V.; Minin, O.V. System of microwave radiovision of three-dimensional objects in real time. In Subsurface Sensing Technologies and Applications II; International Society for Optics and Photonics: Bellingham, WA, USA, 2018; Volume 4129, pp. 616-619.

9. Samura, Y.; Horio, K.; Antipov, V.B.; Shipilov, S.E.; Eremeev, A.I.; Minin, O.V.; Minin, I.V.; Hisatake, S. Characterization of Mesoscopic Dielectric Cuboid Antenna at Millimeter-Wave Band. IEEE Antennas Wirel. Propag. Lett. 2019, 18, $1828-1832$. [CrossRef]

10. Samura, Y.; Yamada, K.; Minin, O.V.; Kanno, A.; Sekine, N.; Nakajima, J.; Minin, I.V.; Hisatake, S. High-gain and Low-profile Dielectric Cuboid Antenna at J-band. In Proceedings of the 2020 14th European Conference on Antennas and Propagation (EuCAP), Copenhagen, Denmark, 15-20 March 2020; pp. 1-4. [CrossRef]

11. Owda, A.Y.; Salmon, N.; Casson, A.J.; Owda, M. The Reflectance of Human Skin in the Millimeter-Wave Band. Sensors 2020, 20, 1480. [CrossRef]

12. Ajito, K.; Ueno, Y. THz Chemical Imaging for Biological Applications. IEEE Trans. Terahertz Sci. Technol. 2011, 1, 293-300. [CrossRef]

13. Taylor, Z.D.; Garritano, J.; Sung, S.; Bajwa, N.; Bennett, D.B.; Nowroozi, B.; Tewari, P.; Sayre, J.W.; Hubschman, J.P.; Deng, S.X.; et al. THz and mm-Wave Sensing of Corneal Tissue Water Content: In Vivo Sensing and Imaging Results. IEEE Trans. Terahertz Sci. Technol. 2015, 5, 184-196. [CrossRef]

14. Pagano, M.; Baldacci, L.; Ottomaniello, A.; de Dato, G.; Chianucci, F.; Masini, L.; Carelli, G.; Toncelli, A.; Storchi, P.; Tredicucci, A.; et al. THz Water Transmittance and Leaf Surface Area: An Effective Nondestructive Method for Determining Leaf Water Content. Sensors 2019, 19, 4838. [CrossRef] [PubMed]

15. Zang, Z.; Wang, J.; Cui, H.L.; Yan, S. Terahertz spectral imaging based quantitative determination of spatial distribution of plant leaf constituents. Plant Methods 2019, 15, 106. [CrossRef] [PubMed] 
16. Delgado Notario, J.A.; Clericò, V.; Diez, E.; Velázquez-Pérez, J.E.; Taniguchi, T.; Watanabe, K.; Otsuji, T.; Meziani, Y.M. Asymmetric dual-grating gates graphene FET for detection of terahertz radiations. APL Photonics 2020, 5, 066102. [CrossRef]

17. Yamada, K.; Samura, Y.; Minin, O.V.; Kanno, A.; Sekine, N.; Nakajima, J.; Minin, I.V.; Hisatake, S. Short-range Wireless Transmitter Using Mesoscopic Dielectric Cuboid Antenna in 300-GHz Band. In Proceedings of the 2020 50th European Microwave Conference (EuMC), Utrecht, The Netherlands, 12-14 January 2021; pp. 195-198. [CrossRef]

18. Golay, M.J.E. Theoretical Consideration in Heat and Infra-Red Detection, with Particular Reference to the Pneumatic Detector. Rev. Sci. Instrum. 1947, 18, 347-356. [CrossRef] [PubMed]

19. Stenger, V.; Shnider, M.; Sriram, S.; Dooley, D.; Stout, M. Thin Film Lithium Tantalate (TFLT) pyroelectric detectors. In Terahertz Technology and Applications V; Sadwick, L.P., O'Sullivan, C.M., Eds.; International Society for Optics and Photonics: Bellingham, WA, USA, 2012; Volume 8261, pp. 174-182.

20. Wang, J.; Gou, J.; Li, W. Preparation of room temperature terahertz detector with lithium tantalate crystal and thin film. AIP Adv. 2014, 4, 027106. [CrossRef]

21. Paulish, A.G.; Gusachenko, A.V.; Morozov, A.O.; Dorozhkin, K.V.; Suslyaev, V.I.; Golyashov, V.A.; Minin, O.V.; Minin, I.V. Characterization of tetraaminediphenyl-based pyroelectric detector from visible to millimeter wave ranges. Opt. Eng. 2019, 59, 1-8. [CrossRef]

22. Müller, R.; Bohmeyer, W.; Kehrt, M.; Lange, K.; Monte, C.; Steiger, A. Novel detectors for traceable THz power measurements. J. Infrared Millim. Terahertz Waves 2014, 35, 659-670. [CrossRef]

23. Müller, R.; Gutschwager, B.; Hollandt, J.; Kehrt, M.; Monte, C.; Müller, R.; Steiger, A. Characterization of a Large-Area Pyroelectric Detector from $300 \mathrm{GHz}$ to $30 \mathrm{THz}$. J. Infrared Millim. Terahertz Waves 2015, 36, 654-661. [CrossRef]

24. Rogalski, A. Infrared Detectors; CRC Press: Boca Raton, FL, USA, 2010.

25. Neumann, N.; Banta, V. Comparison of Pyroelectric and Thermopile Detectors. In Proceedings of the AMA Conferences 2013, Nurnberg, Germany, 14-16 May 2013; Volume 8261, pp. 139-143. [CrossRef]

26. Zhao, J.; Zhu, R.; Chen, J.; Zhang, M.; Feng, P.; Jiao, J.; Wang, X.; Luo, H. Enhanced temperature stability of compensated pyroelectric infrared detector based on Mn:PMN-PT single crystals. Sens. Actuators A Phys. 2021, 327, 112757. [CrossRef]

27. Ng, D.K.T.; Ho, C.P.; Zhang, T.; Xu, L.; Siow, L.Y.; Chung, W.W.; Cai, H.; Lee, L.Y.T.; Zhang, Q.; Singh, N. CMOS compatible MEMS pyroelectric infrared detectors: from AlN to ScAIN. In MOEMS and Miniaturized Systems XX; International Society for Optics and Photonics: Bellingham, WA, USA, 2021; Volume 11697, pp. 152-157.

28. Huang, Y.D.; Yu, Y.; Qin, H.; Sun, J.D.; Zhang, Z.P.; Li, X.X.; Huang, J.J.; Cai, Y. Plasmonic terahertz modulator based on a grating-coupled two-dimensional electron system. Appl. Phys. Lett. 2016, 109, 201110. [CrossRef]

29. Tu, X.; Kang, L.; Wan, C.; Xu, L.; Mao, Q.; Xiao, P.; Jia, X.; Dou, W.; Chen, J.; Wu, P. Diffractive microlens integrated into Nb5N6 microbolometers for THz detection. Opt. Express 2015, 23, 13794-13803. [CrossRef]

30. Xiao, P.; Tu, X.; Kang, L.; Jiang, C.; Zhai, S.; Jiang, Z.; Pan, D.; Chen, J.; Jia, X.; Wu, P. Reflective grating-coupled structure improves the detection efficiency of THz array detectors. Sci. Rep. 2018, 8, 8032. [CrossRef]

31. Minin, O.V.; Minin, I.V.; Meziani, Y.M.; Hisatake, S. Improvement of a Point-Contact Detector Performance Using the Terajet Effect Initiated by Photonics. Opt. Eng. 2020, 60, 082004. [CrossRef]

32. Minin, I.V.; Calvo-Gallego, J.; Velázquez-Pérez, J.E.; Salvador-Sánchez, J.; Delgado-Notario, J.A.; Fobelets, K.; Ferrando-Bataller, M.; Minin, O.V.; Meziani, Y.M. Responsivity enhancement of a strained silicon field-effect transistor detector at $0.3 \mathrm{THz}$ using the terajet effect. Opt. Lett. 2021, 46, 3061-3064. [CrossRef] [PubMed]

33. Öjefors, E.; Lisauskas, A.; Glaab, D.; Roskos, H.G.; Pfeiffer, U.R. Terahertz Imaging Detectors in CMOS Technology. J. Infrared Millim. Terahertz Waves 2009, 30, 1269-1280. [CrossRef]

34. Huang, Z.; Li, Z.; Dong, H.; Yang, F.; Yan, W.; Wang, X. Novel Broadband Slot-Spiral Antenna for Terahertz Applications. Photonics 2021, 8, 123. [CrossRef]

35. Yang, J.; jing Gong, X.; dong Zhang, Y. Research of an infrared pyroelectric sensor based THz detector and its application in CW THz imaging. In International Symposium on Photoelectronic Detection and Imaging 2009: Terahertz and High Energy Radiation Detection Technologies and Applications; International Society for Optics and Photonics: Bellingham, WA, USA, 2009; Volume 7385, p. 738521.

36. Murfet, D. Small-Size Pyroelectric Detector MG33 of Optical Radiation, Vostok Science and Production Enterprise. Available online: http:/ / www.nzpp.ru/product/gotovye-izdeli/fotopriemnye-ustroystva/MG33.pdf (accessed on July 29, 2021)

37. Ivanov, S.D.; Kostsov, E.G. Thermal detectors of uncooled multi-element infrared imaging arrays. I. Thermally insulated elements. Optoelectron. Instrum. Data Process. 2015, 51, 601-608. [CrossRef]

38. Dooley, D. Sensitivity of broadband pyroelectric terahertz detectors continues to improve. Laser Focus World $2010,46,49$.

39. Dégardin, A.; Jagtap, V.; Razanoelina, M.; Galiano, X.; Tonouchi, M.; Kreisler, A. Y-Ba-Cu-O semiconducting pyroelectric thermal sensors: design and test of near-infrared amorphous thin film detectors and extension to antenna-coupled THz devices. In Millimetre Wave and Terahertz Sensors and Technology XII; Salmon, N.A., Gumbmann, F., Eds.; International Society for Optics and Photonics: Bellingham, WA, USA, 2019; Volume 11164, pp. 68-80.

40. Kuznetsov, S.A.; Paulish, A.G.; Navarro-Cía, M.; Arzhannikov, A.V. Selective Pyroelectric Detection of Millimetre Waves Using Ultra-Thin Metasurface Absorbers. Sci. Rep. 2016, 6, 21079. [CrossRef]

41. Pacheco-Peña, V.; Beruete, M.; Minin, I.V.; Minin, O.V. Terajets produced by dielectric cuboids. Appl. Phys. Lett. 2014, 105, 084102. [CrossRef] 
42. Minin, I.V.; Minin, O.V. Terahertz artificial dielectric cuboid lens on substrate for super-resolution images. Opt. Quantum Electron. 2017, 49, 326. [CrossRef]

43. Yue, L.; Yang, B.; Monks, J.; Z., W.; Tung, N.; Lam, V.; Minin, O.V.; Minin, I.V. A millimetre-wave cuboid solid immersion lens with intensity-enhanced amplitude mask apodization. J. Infrared Millim. Terahertz Waves 2018, 39, 546-552. [CrossRef]

44. Nguyen Pham, H.H.; Hisatake, S.; Minin, I.V.; Minin, O.V.; Nagatsuma, T. Three-dimensional direct observation of Gouy phase shift in a terajet produced by a dielectric cuboid. Appl. Phys. Lett. 2016, 108, 191102. [CrossRef]

45. Minin, O.V.; Minin, I.V. Method of Registration of Electromagnetic Radiation in IR, Microwave and THz Range of Wavelengths. Russia Patent 2,655,714, 12 December 2016.

46. Minin, I.V.; Minin, O.V.; Delgado-Notario, J.A.; Calvo-Gallego, J.; Velázquez-Pérez, J.E.; Ferrando-Bataller, M.; Meziani, Y.M. Improvement of a Terahertz Detector Performance Using the Terajet Effect in a Mesoscale Dielectric Cube: Proof of Concept. Phys. Status Solidi (RRL)-Rapid Res. Lett. 2020, 14, 1900700. [CrossRef]

47. Kompfner, R.; Williams, N.T. Backward-Wave Tubes. Proc. IRE 1953, 41, 1602-1611. [CrossRef]

48. D'Angelo, F.; Mics, Z.; Bonn, M.; Turchinovic, D. Ultra-broadband THz time-domain spectroscopy of common polymers using THz air photonics. Opt. Express 2014, 22, 12475. [CrossRef] [PubMed]

49. Folks, W.R.; Pandey, S.K.; Boreman, G. Refractive Index at THz Frequencies of Various Plastics. In Optical Terahertz SCIENCE and Technology; Optical Society of America: California, CA, USA, 2007; p. MD10. [CrossRef]

50. Jin, Y.S.; Kim, G.J.; Jeon, S.G. Terahertz Dielectric Properties of Polymers. J. Korean Phys. Soc. 2006, 49, $513-517$.

51. Hotelling, H. The Generalization of Student's Ratio. Ann. Math. Stat. 1931, 2, 360-378. [CrossRef] 